\section{In Vitro Clonal Propagation of Vanilla (Vanilla planifolia 'Andrews')}

\author{
Hilda E. Lee-Espinosa, Joaquín Murguía-González, \\ Benjamín García-Rosas, and Ana L. Córdova-Contreras
}

Fac. C. Biológicas y Agropecuarias de Córdoba, Ver., Km. 1, Universidad Veracruzana, Peñuela-Amatlán de los Reyes, CP 94950, Veracruz, México

Antonio Laguna-Cerda

Fac. C. Agricolas, Universidad Autónoma del Estado de México, Campus El Cerrillo Km. 15 carretera Toluca-Ixtlahuaca, Estado de México, México

Javier O. Mijangos-Cortés

Unidad de Recursos Naturales, Centro de Investigación Cientifica de Yucatán, Calle 43 \# 130, Chuburná de Hidalgo, Mérida, Yucatán, C.P. 97200, México

\section{Luis F. Barahona-Pérez}

Unidad de Materiales, Centro de Investigación Cientifica de Yucatán, Calle 43 \# 130, Chuburná de Hidalgo, Mérida, Yucatán, C.P. 97200, México

\section{Lourdes G. Iglesias-Andreu}

Lab. Biotecnología y Ecología Aplicada (LABIOTECA), Universidad Veracruzana, Campus para la Cultura, las Artes y el Deporte, Xalapa, Veracruz, C.P. 91001, México

\section{Nancy Santana-Buzzy ${ }^{1}$}

Unidad de Bioquímica y Biología Molecular de Plantas, Centro de Investigación Cientifica de Yucatán, Calle 43 \# 130, Chuburná de Hidalgo, Mérida, Yucatán, C.P. 97200, México

Additional index words. Orchidaceae, micropropagation, rooting, acclimatization, 6-benzylaminopurine (BA), $\alpha$-naphthalene acetic acid (NAA), thidiazuron (TDZ)

\begin{abstract}
A complete and efficient regeneration protocol was developed for Vanilla planifolia 'Andrews', an endangered orchid species that represents an important crop in several tropical countries. Axillary buds excised from the first to the eighth node, considering the first to fourth nodes as "young" (zone 1) and the fifth to eighth as "mature" (zone 2), were cultured on Murashige and Skoog (MS) medium supplemented with 5.73, 7.64, 9.55, or $11.46 \mu M$ 6-benzylaminopurine (BA) for shoot induction and in combination with $4.45 \mu \mathrm{M}$ naphthalene acetic acid (NAA) to induce multiple shoot proliferation. Cytokinin concentration and bud position in the stem had a significant effect on the number of shoots regenerated. The greatest shoot formation per explant, for the two tested zones, was obtained with 9.55 $\mu$ M BA on MS medium supplemented with $100 \mathrm{mg} \cdot \mathrm{L}^{-1}$ myoinositol, $150 \mathrm{mg} \cdot \mathrm{L}^{-1}$ citric acid, $100 \mathrm{mg} \cdot \mathrm{L}^{-1}$ ascorbic acid, and $20 \mathrm{~g} \cdot \mathrm{L}^{-1}$ sucrose. Young buds from zone 1 were able to form an average of $18.5 \pm 2.4$ shoots per explant, whereas buds from zone 2 induced a maximum of $11.0 \pm 1.0$ shoots per explant. Plants of 2 to $3 \mathrm{~cm}$ height developed a root system in half-strength MS medium supplemented with $0.44 \mu \mathrm{M}$ NAA and, once they reached $5 \mathrm{~cm}$ height on average, were transferred to greenhouse conditions for their acclimatization where a $100 \%$ rate survival was achieved. The optimal use of both young and mature buds from each mother plant to induce adventitious shoots permitted a marked increase in the number of shoots per explant. By using all buds from the upper stem part (zone $1+$ zone 2 ) and subculturing every $90 \mathrm{~d}$, the multiplication rate was 1.1 to $1.86 \times 10^{5}$ shoots per bud per year.
\end{abstract}

\footnotetext{
Received for publication 27 Sept. 2007. Accepted for publication 25 Oct. 2007.

We thank the Vanilla Farmers Union of Papantla, Veracruz, México, for supplying Vanilla planifolia 'Andrews' plants; the University of Veracruz for financial support of this project; and the PROMEP fellowship support.

${ }^{1}$ To whom reprints requests should be addressed; e-mail buzzy@cicy.mx
}

Vanilla planifolia 'Andrews' (vanilla) is the natural source of the flavoring and aromatizing vanillin, the main flavor component of cured vanilla beans used in many industries (food, liquor, soft drinks, pharmaceutical, cosmetic, tobacco, and handcrafts) and considered to be of better quality than the synthetic product. V. planifolia 'Andrews', also known as Vanilla fragrans (Salisb) (Bouriquet, 1954), is a tropical climbing orchid with origins in Mexico and Central America (Funk and Brodelius, 1990). Despite Mexico being considered as the origin and domestication center of Vanilla planifolia 'Andrews', now this is an endangered Mexican species, mainly as a result of reduced multiplication rates of this species through traditional production techniques, unsuitable farming labor, and several fungal damages and infections. Because of this situation, Mexican vanilla growers confront many challenges when producing vanilla vines that meet official standards, foreign competition, and miss the chance to produce enough plant material to satisfy an increasing demand of vanilla vines. Therefore, more efficient methods are required for large-scale elite plants production. Morel (1960) was the first to demonstrate the possibility of cloning virus-free orchids through apex culture (Goh, 1983). However, in monopodial orchids such as vanilla, meristem culture requires the removal of the apical shoot, which results in retarded growth and development of mother plants. Over the last few decades, the possibility of propagating orchids in vitro using other parts of the plant as explants has been investigated. There are reports of in vitro regeneration for this species through callus culture (Davidonis and Knorr, 1991; Gu et al., 1978), protocorms and root apex (Philip and Nainar, 1986), axillary buds (George and Ravishankar, 1997; Giridhar and Ravishankar, 2004; Kononowicz and Janick, 1984), and shoot tips (Geetha and Sudheer, 2000). However, the efficiency of these reported protocols is still low, probably as a result of phenolic compounds that accumulate in explant tissues during in vitro establishment. Given the increased interest and worldwide demand for elite Vanilla planifolia A. plants, we established an efficient largescale micropropagation protocol for this species through the optimal use of axillary buds from each mother plant to achieve the highest number of adventitious shoots per bud per plant and to promote successful acclimatization of the regenerated plants.

\section{Materials and Methods}

Explant preparation. Nodes were collected from 3-year-old vanilla ( $V$. planifolia A.) plants grown in Papantla, Veracruz, Mexico. Axillary buds, between 3 and $5 \mathrm{~mm}$ in diameter, were excised from the first to the eighth node of the stem and eventually distinguished in two zones: zone 1, including buds between first to fourth nodes (young buds), and zone 2, including buds between fifth and eighth nodes (mature buds).

Isolated buds were disinfected with a surfactant solution ( 1 to 2 drops of Tween20; ICI Americas; in $1 \mathrm{~L}$ distilled water) and washed under a slow flow of tap water for $45 \mathrm{~min}$, then a higher flow for 10 more min. Subsequently, buds were consecutively submerged in commercial sodium hypochlorite (6\% active chlorine) diluted at different 
concentrations: 1$)$ at $10 \%(\mathrm{v} / \mathrm{v})$ for $20 \mathrm{~min} ; 2)$ at $5 \%(\mathrm{v} / \mathrm{v})$ for $10 \mathrm{~min}$; and 3$)$ at $2 \%(\mathrm{v} / \mathrm{v})$ for $2 \mathrm{~min}$. The buds were then rinsed four to five times with sterilized distilled water containing $150 \mathrm{mg} \cdot \mathrm{L}^{-1}$ citric acid and $100 \mathrm{mg} \cdot \mathrm{L}^{-1}$ ascorbic acid.

Shoot induction and proliferation. The basal nutrient medium recommended by Murashige and Skoog (MS) (Murashige and Skoog, 1962) was used in all culture media supplemented with $100 \mathrm{mg} \cdot \mathrm{L}^{-1}$ myoinositol, $150 \mathrm{mg} \cdot \mathrm{L}^{-1}$ citric acid, $100 \mathrm{mg} \cdot \mathrm{L}^{-1}$ ascorbic acid, $20 \mathrm{~g} \cdot \mathrm{L}^{-1}$ sucrose, and $5 \mathrm{~g} \cdot \mathrm{L}^{-1}$ agar-agar (Sigma-Aldrich Ltd. Co.); pH was adjusted to 5.7 before autoclaving at $1 \mathrm{~kg} \cdot \mathrm{cm}^{-2}$ for $15 \mathrm{~min}$ and $120{ }^{\circ} \mathrm{C}$. Culture vessels used were $125-\mathrm{mL}$ baby food jars with $20 \mathrm{~mL}$ of medium. All cultures were incubated at $24 \pm 1{ }^{\circ} \mathrm{C}$ and $16 / 8 \mathrm{~h}$ photoperiod (40.5 $\mu \mathrm{mol} \cdot \mathrm{m}^{-2} \cdot \mathrm{s}^{-1}$ ). For shoot induction, the buds were cultivated at different concentrations of 6-benzylaminopurine (BA): 5.73, 7.64, 9.55, and $11.46 \mu \mathrm{M}$; the shoots obtained $(0.5$ to $0.7 \mathrm{~cm}$ height) after 30 to $45 \mathrm{~d}$ were transferred to a proliferation medium containing the same cytokinin concentrations used for the induction stage with the addition of $4.45 \mu \mathrm{M}$ naphthalene acetic acid (NAA) in each treatment. Fifteen explants were used for each treatment and the experiments were carried out four times. The smallest shoots (less than $5 \mathrm{~mm}$ ) induced after $30 \mathrm{~d}$ in solid medium were transferred to $250-\mathrm{mL}$ Erlenmeyer flasks containing $50 \mathrm{~mL}$ MS liquid medium supplemented with $100 \mathrm{mg} \cdot \mathrm{L}^{-1}$ myoinositol, $150 \mathrm{mg} \cdot \mathrm{L}^{-1}$ citric acid, $100 \mathrm{mg} \cdot \mathrm{L}^{-1}$ ascorbic acid, $20 \mathrm{~g} \cdot \mathrm{L}^{-1}$ sucrose, and $9.55 \mu \mathrm{M} \mathrm{BA}$ and incubated at $24 \pm 1{ }^{\circ} \mathrm{C}$ and $16 / 8 \mathrm{~h}$ photoperiod $\left(54 \mu \mathrm{mol} \cdot \mathrm{m}^{-2} \cdot \mathrm{s}^{-1}\right)$. Each flask contained 10 shoots and they were cultured with agitation on reciprocal shaker at $120 \mathrm{rpm}$. Two subcultures were made every $15 \mathrm{~d}$ to maintain shoot viability for multiplication. In all the experiments, a reference consisting of MS medium without growth regulators was used.

Shoot rooting. Shoots over $2.0 \mathrm{~cm}$ height were individualized and subcultured in halfstrength MS media supplemented with 100 $\mathrm{mg} \cdot \mathrm{L}^{-1}$ myoinositol, $20 \mathrm{~g} \cdot \mathrm{L}^{-1}$ sucrose, $5 \mathrm{~g} \cdot \mathrm{L}^{-1}$ agar-agar, and different concentrations of NAA $(0.44,2.22,4.45$, and $6.67 \mu \mathrm{M})$ to induce rooting. Fifteen shoots were used for each treatment (three shoots per jar). Shoots for root induction were incubated at $24 \pm 1{ }^{\circ} \mathrm{C}$ and $16 / 8 \mathrm{~h}$ photoperiod $\left(54 \mu \mathrm{mol} \cdot \mathrm{m}^{-2} \cdot \mathrm{s}^{-1}\right)$. The experiment was carried out four times and a reference consisting of half-strength MS medium without growth regulators was used. Culture time was $30 \mathrm{~d}$ or until root presence was observed.

Acclimatization. Vanilla planifolia A. shoots (average height $5 \mathrm{~cm}$ ) were washed with abundant running tap water to remove culture medium and transferred to potting medium (peatmoss and agrolite, 1:1) for their acclimatization in the greenhouse. Conditions at the Biological and Agricultural Sciences Faculty Greenhouse, Veracruz University, Córdoba, Veracruz, México, were $30{ }^{\circ} \mathrm{C}$ temperature with a high relative humidity $(\approx 90 \%)$ and a $16 / 8 \mathrm{~h}$ photoperiod $(87.8$ $\left.\mu \mathrm{mol} \cdot \mathrm{m}^{-2} \cdot \mathrm{s}^{-1}\right)$. Vanilla planifolia A. plantlets were maintained under these conditions for $30 \mathrm{~d}$, and the survivors were transplanted to soil in the field.

Statistical analysis. A completely random design was used with 15 replications for each treatment, and each experiment was carried out four times. The experimental variables were subjected to a simple classifying variance analysis using the PROC ANOVA procedure from the SAS statistical program (version 6.12; SAS Institute, Cary, NC). Mean comparisons were carried out using the Tukey test $(\alpha=0.05)$ (Steel and Torrie, 1980). The STATISTICA (version 5; STAT SOFT Inc., Tulsa, OK) program was used to perform a cluster analysis using the Euclidian distance and the algorithm "unweighted pair group method with arithmetic mean" and a principal components analysis.

\section{Results}

Shoot induction and proliferation. As a result of exposing the vanilla buds to different treatments, regardless of which zone of the stem they were isolated from, it was possible to observe a linear effect in explant response (number of shoots per explant) with cytokinin concentration until an optimum was reached $(9.55 \mu \mathrm{M}$ BA), after which the capacity for shoot emission decreased significantly, as observed in Figure 1A-B. The best BA concentration for shoot induction and proliferation was $9.55 \mu \mathrm{M}$ using buds from both zones. Young buds formed an average of $18.5 \pm 2.4$ shoots per explant (Fig. 1A), whereas mature buds reached a maximum of $11.0 \pm 1.0$ shoots per explant (Fig. 1B). As a result, it is possible to estimate an approximate production of 100,000 to 150,000 plantlets per explant per year using buds from the first to the eighth node with a multiplication rate between 1.8 and $1.1 \times 10^{5}$ shoots per bud per year. Significant differences in the regenerative capacity of the buds can be appreciated (Fig. 1C) depending on the zone of the stem where buds were isolated (Fig. 2A-B) and regardless of the treatments evaluated. Young buds induced an average of 11.2 shoots per explant, whereas mature buds induced 6.2 shoots per explant. These results
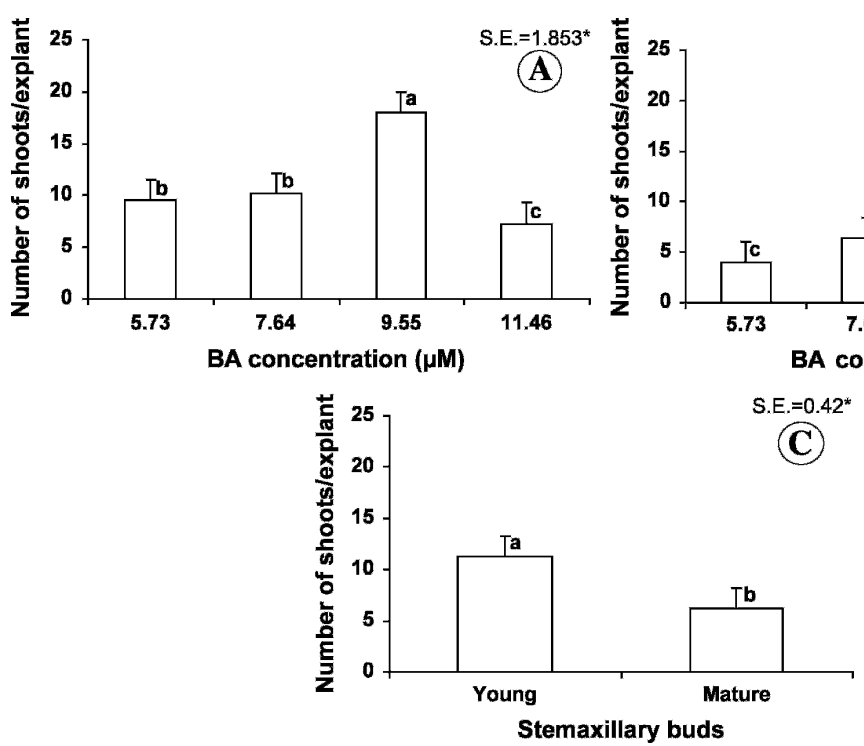

Fig. 1. Effect of 6-benzylaminopurine on shoot induction in Vanilla planifolia axillary buds originating from two different stem zones: (A) shoot induction in young buds situated between the first and fourth node (zone 1); (B) shoot induction in mature buds situated between the fifth and eighth node (zone 2); (C) shoot induction in young (zone 1) and mature buds (zone 2) with independence of the evaluated treatments. Averages with different letters are significantly different (Tukey, $\alpha=0.05$ ).
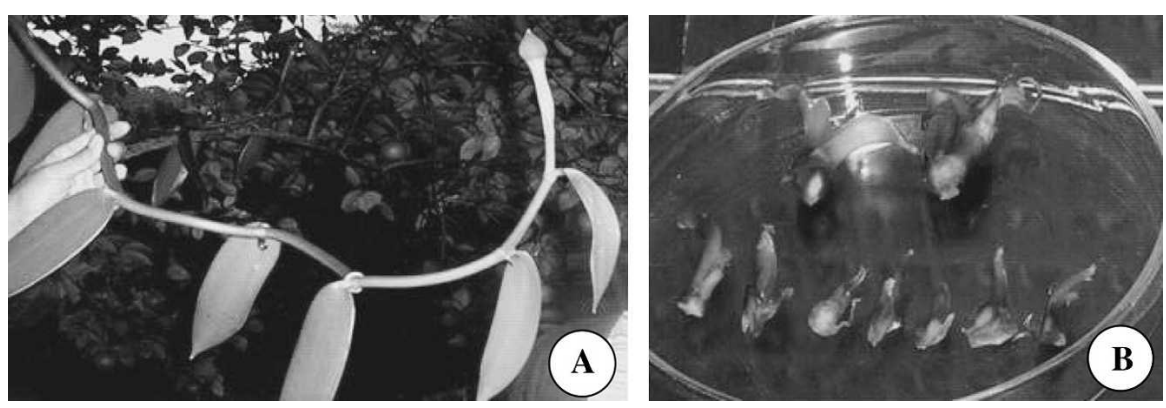

Fig. 2. Vanilla planifolia 'Andrews': (A) segment of stem showing nodes where axillary buds were isolated; (B) excised nodes. 
suggest that bud position in the stem (physiological age) is a determining factor for adventitious multiple soot induction capacity in this species. Cluster analysis results showed two well-defined groups (Fig. 3A):
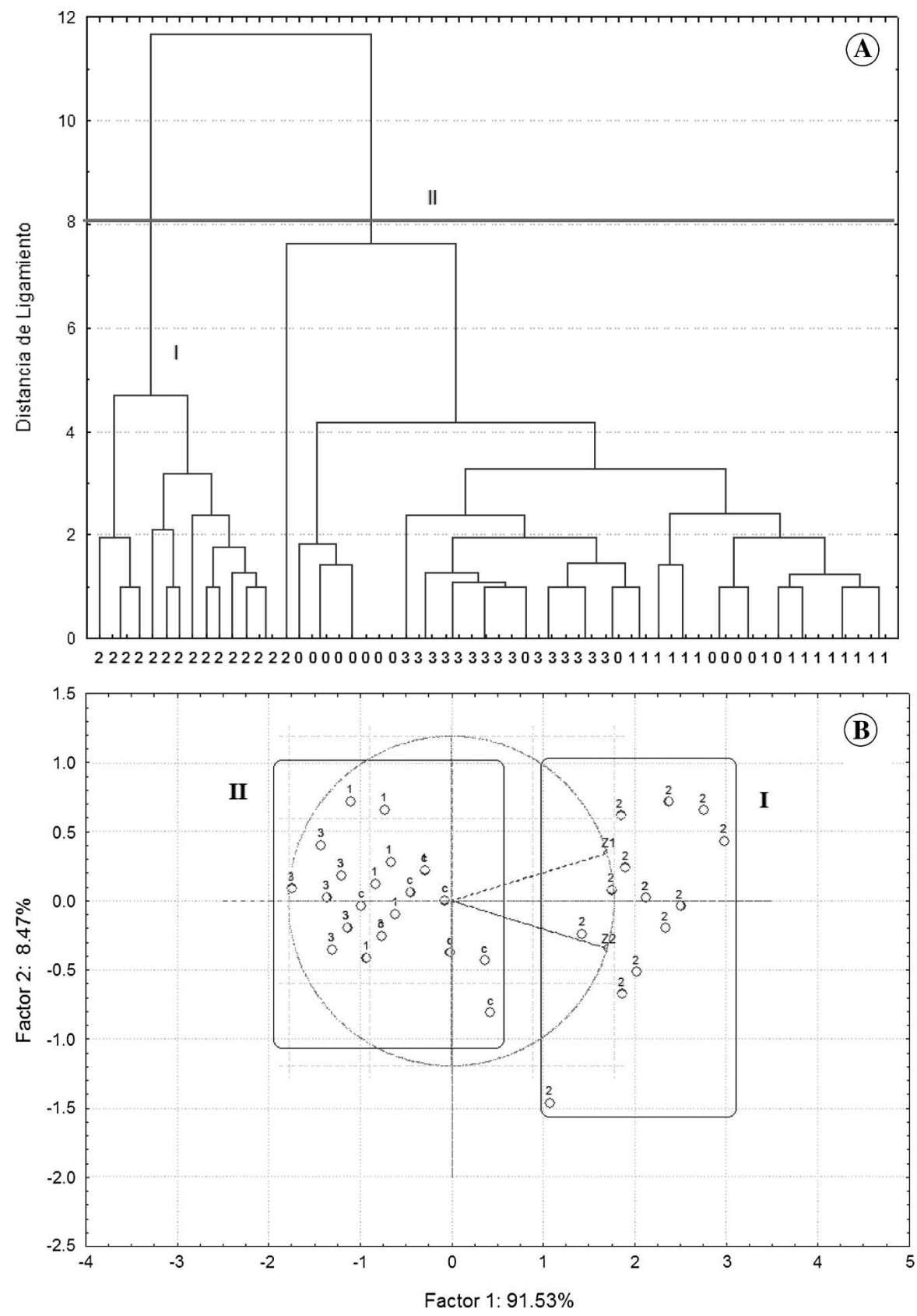

Fig. 3. The unweighted pair group method of arithmetic average (UPGMA) dendrogram of the 6benzylaminopurine $(\mathrm{BA})$ treatments $(0=7.64 ; 1=5.73 ; 2=9.55$, and $3=11.46 \mu \mathrm{M})$ on shoot proliferation induction in Vanilla planifolia 'Andrews' axillary buds: (A) UPGMA cluster analysis from the similarity matrix obtained using Euclidean distance to classify the treatments; (B) principal components analysis showing relationships among treatments based on the stem origin of axillary buds $(\mathrm{c}=\mathrm{T} 0,1=\mathrm{T} 1,2=\mathrm{T} 2,3=\mathrm{T} 3)$.

Table 1. Descriptive statistics (average values, variance, and SD) comparing clusters formed in zones 1 and 2.

\begin{tabular}{lccccccc}
\hline & \multicolumn{3}{c}{ Cluster I } & & \multicolumn{3}{c}{ Cluster II } \\
\cline { 2 - 4 } \cline { 6 - 8 } Stem zones & Average & SD & Variance & & Average & SD & Variance \\
\hline Zone 1 & 18.57 & 2.44 & 5.95 & & 9.00 & 1.60 & 2.57 \\
Zone 2 & 11.00 & 1.03 & 1.07 & & 4.73 & 2.02 & 4.10 \\
\hline
\end{tabular}

ments with $5.73,7.64$, and $11.46 \mu \mathrm{M}$ BA, which was shown to be heterogeneous. Table 1 shows the descriptive statistics for each of the clusters formed in both groups. In treatments with 5.73 and $11.46 \mu \mathrm{M} \mathrm{BA}$, a lower shoot proliferation of 7.0 and 7.4 shoots per explant was obtained, respectively. These results were surpassed by $7.64 \mu \mathrm{M} \mathrm{BA}$, which induced an average of 9.2 shoots per explant. Moreover, the multiplication rate obtained with $9.55 \mu \mathrm{M}$ BA for Vanilla planifolia A. greatly surpasses the rates reported to date for this species (Cervera and Madrigal, 1981; Ganesh et al., 1996; Geetha and Sudheer, 2000; George and Ravishankar, 1997; Giridhar and Ravishankar, 2004; Kononowicz and Janick, 1984; Philip and Nainar, 1986). It is also important to emphasize that although significant differences were found in the average number of shoots obtained with buds isolated from zones 1 and 2 (Fig. 1C), BA at $9.55 \mu \mathrm{M}$ induced the greatest number of shoots for both zones, as shown by the principal components analysis (Fig. 3B). With these results, it is possible to conclude that $9.55 \mu \mathrm{M}$ BA proved to be the best cytokinin concentration for shoot induction and proliferation in Vanilla planifolia A. After $30 \mathrm{~d}$ of culture, the shoots obtained showed a vigorous development with intense bright green leaves and an average of five to six and a half shoots per explant were induced, depending on the zone from which they originated. After $45 \mathrm{~d}$, there was a considerable increase in the proliferation and development of new shoots, achieving an average of 18.6 shoots per explant after 3 months of culture (Fig. 4).

Shoot rooting. After 4 weeks of culture, significant differences between rooting treatments could be observed (Fig. 5). Individualized adventitious shoots $(\approx 5.0 \mathrm{~cm}$ in height) developed an efficient root system with $0.445 \mu \mathrm{M}$ NAA, which proved to be the best concentration not only for root induction, but also to promote a harmonic development of rooted plants. Moreover, an inverse relationship was observed between NAA concentrations $(0.445,2.22,4.45$, and $6.67 \mu \mathrm{M})$ and root development; as a result of this effect, lower NAA concentrations $(0.445$ $\mu \mathrm{M}$ NAA) yielded a higher number of roots per shoot. An inhibitory effect was observed

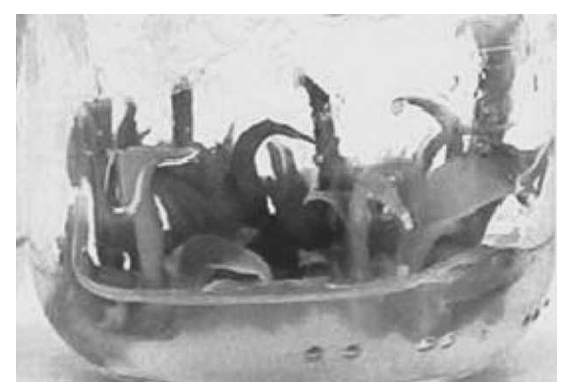

Fig. 4. Vanilla planifolia 'Andrews' multiple shoots proliferating at $60 \mathrm{~d}$ of culture in Murashige and Skoog medium supplemented with $9.55 \mu \mathrm{M}$ 6-benzylaminopurine. 
on roots and plant development with the increase of NAA concentrations (Fig. 6B).

Acclimatization. High heterogeneity was observed in the development of the plantlets at the beginning of the acclimatization process (potting and greenhouse transfer) as can be observed in Figures 6C and D. After 45 d, when plantlets were transferred to soil at field conditions, an average of three pairs of leaves per plant was achieved (Fig. 6E). The survival rate of plantlets in this phase was $90 \%$ to $95 \%$. Four months after transplanting, vanilla plants showed vigorous development with a $100 \%$ survival rate (Fig. $6 \mathrm{~F}$ ).

\section{Discussion}

In this protocol, the optimal use of explants in simple culture media highly improved the Vanilla planifolia 'Andrews' micropropagation system. The use of buds between the first and the eighth node of the stem (zone $1+$ zone 2 ) reduced the number of mother plants used; in contrast, the protocols reported to date, in which nodal sections are the explant source, are based on the use of buds located exclusively closer to the apical zone of the stem (first to third node) (Cervera and Madrigal, 1981; Ganesh et al., 1996; Geetha and Sudheer, 2000; George and Ravishankar, 1997; Giridhar and Ravishankar, 2004; Kononowicz and Janick, 1984; Philip and Nainar, 1985) resulting in a reduction of multiplication rates to half the values obtained in this study. The induction and proliferation of adventitious shoots were achieved in only one culture medium (MS + $9.55 \mu \mathrm{M}$ BA) regardless of bud origin (zone 1 or zone 2). Elongation and rooting of isolated shoots was also achieved in one culture medium (half-strength MS + $0.44 \mu \mathrm{M}$ NAA) with low auxin concentration. This represented a great advantage, because in most cases, it is necessary to induce rooting either in vitro or ex vitro through the application of higher auxin concentrations. With this suitable for large-scale micropropagation protocol, the possibility to obtain $18.5 \pm 2.4$ shoots per explant was demonstrated when young buds from the first to fourth node (zone 1) are subcultured every 3 months, whereas up to $11.0 \pm 1.0$ shoots per explant can be obtained from buds between the fifth and eighth node. By using all the buds from the upper part of the stem (zone $1+$ zone 2 ) with subcultures every 3 months, it is possible to estimate a multiplication rate for vanilla, between 1.1 to $1.8 \times 10^{5}$ shoots per bud per year, for an approximate production of 100,000 to 150,000 plantlets per explant used from each mother plant in 1 year. Giridhar and Ravishankar (2004), working with this species, reported a multiplication rate of $17 \pm$ 2.5 using combinations of $8.87 \mu \mathrm{M} \mathrm{BA}$ and zeatin or thidiazuron in addition to coconut water $(10 \%)$ with subsequent subcultures in BA or NAA for shoot proliferation, which represent an increase in costs of the micropropagated plants produced because of the several cytokinins and auxins included in all media. In this study, the possibility to make

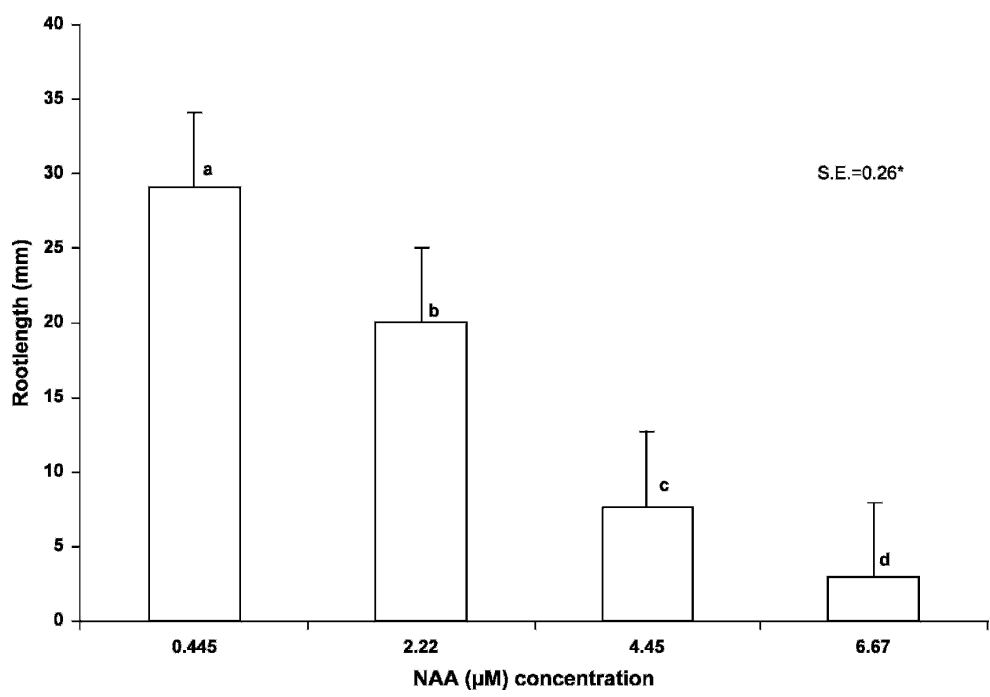

Fig. 5. Effect of naphthalene acetic acid concentrations on the length and root induction in Vanilla planifolia 'Andrews' isolated shoots. Averages with different letters are significantly different (Tukey, $\alpha=0.05)$.
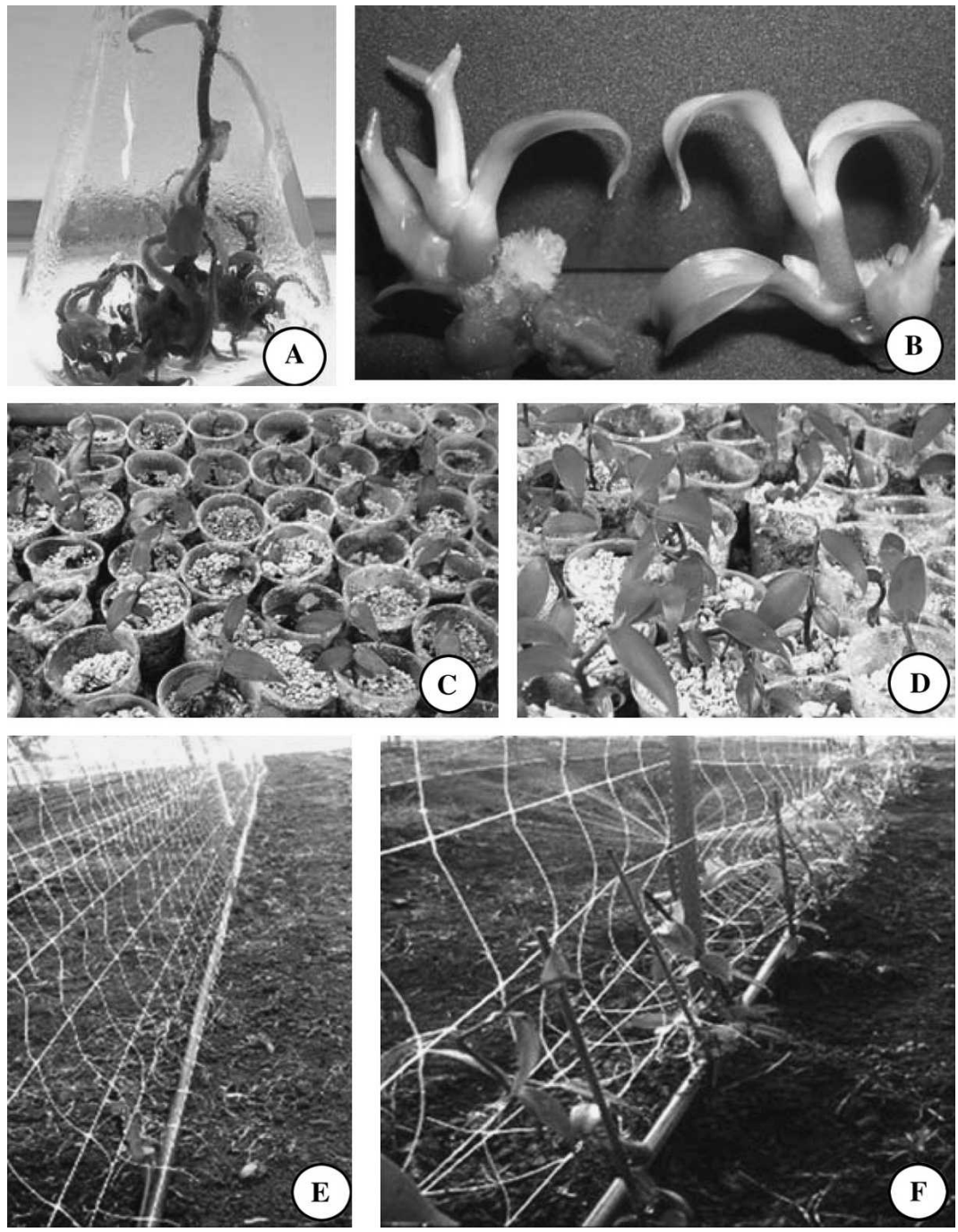

Fig. 6. Adventitious shoot regeneration from in vitro cultured axillary buds, in vitro rooting, and acclimatization of Vanilla planifolia 'Andrews' plantlets: (A) plants developed and rooted in Murashige and Skoog (MS) medium supplemented with $0.445 \mu \mathrm{M}$ naphthalene acetic acid (NAA); (B) subcultured shoots on MS medium with $6.67 \mu \mathrm{M}$ NAA; note the absence of roots and poor leaf development; (C) plantlets in process of acclimatization at the moment of transferring to substrate; (D) plantlets in the greenhouse (6 weeks after potting); (E) plantlets at the moment of transplanting to soil in the field; (F) plants after 4 months in soil. 
the micropropagation process more efficient by developing a system with a highest shoot proliferation (18.5 \pm 2.4 shoots) including shorter time periods for induction ( 30 to $45 \mathrm{~d}$ ) and multiple shoot proliferation $(30 \mathrm{~d})$ is proposed. We determined the use of 9.55 $\mu \mathrm{M}$ BA, a higher concentration than used in other reported protocols, for both induction and proliferation steps; however, it simplifies and enhances the efficiency of our developed system by reducing the incubation time required for shoot induction and proliferation. George and Ravishankar (1997) reported a protocol that included $7.64 \mu \mathrm{M}$ BA to induce an average of 5.7 shoots per explant in a $90-\mathrm{d}$ period, which means a longer time for shoot induction. In general, the protocols previously reported require 4 to 6 months to complete only shoot induction and proliferation stages. Ganesh et al. (1996) mentioned that the main difficulties in the propagation of vanilla species through node culture were: 1) the adverse effect of ethylene that can be accumulated in vessel cultures and inhibit shoot proliferation; and 2) highly condensed internodes. To overcome these problems, they supplemented all used media with $20 \mathrm{mg} \cdot \mathrm{L}^{-1} \mathrm{AgNO}_{3}$ as an ethylene inhibitor and $0.1 \mathrm{mg} \cdot \mathrm{L}^{-1} \mathrm{GA}_{3}$ to induce shoot elongation; additionally, they used $1 \mathrm{mg} \cdot \mathrm{L}^{-1}$ $\mathrm{BA}$ to induce shoot proliferation, and the subculture time was extended to $135 \mathrm{~d}$. In our study, subculturing into media lacking $\mathrm{AgNO}_{3}$ and $\mathrm{GA}_{3}$, and supplemented with BA $(9.55 \mu \mathrm{M})$ at 30 -d subculture periods, allowed efficient shoot proliferation with normal elongated internodes, probably as a result of shorter subculturing times and a higher BA concentration, which avoid ethylene accumulation, and shoots $5 \mathrm{~cm}$ in length could be obtained 3 months after culture initiation. It is widely known that $V$. planifolia 'Andrews' is the only orchid species of great industrial value, because it is the natural source of the flavoring compound known as vanilla; therefore, a highly reliable clonal propagation system is required to produce uniform plants with appropriate characteristics for intensive cultivation. As a result of this study, a rapid, simple, and efficient large-scale protocol for in vitro clonal propagation of Vanilla planifolia 'Andrews' was established, which is probably the most efficient procedure reported to date. Establishing rapid and simple plant production procedures with higher multiplication rates than those obtained with traditional methods is undoubtedly of great value. With this efficient micropropagation protocol, we are contributing to improve the large-scale production of élite Vanilla planifolia 'Andrews' plants widely used for commercial production and industrial purposes.

\section{Literature Cited}

Bouriquet, G. 1954. Le vanillier et la vanille dans le monde. Ed. Lechevalier, Paris.

Cervera, E. and R. Madrigal. 1981. In vitro propagation of vanilla (Vanilla planifolia A.). Environ. Exp. Bot. 21:441. (abstr.).

Davidonis, G. and D. Knorr. 1991. Callus formation and shoot regeneration in Vanilla planifolia. Food Biotechnol. 5:59-66.
Funk, C. and P. Brodelius. 1990. Influence of growth regulators and an elicitor on phenylpropanoid metabolism in suspension cultures of Vanilla planifolia. Phytochemistry 29:845848.

Ganesh, D.S., H.L. Sreenath, and G. Jayashree. 1996. Micropropagation of vanilla through node culture. J. Plantation Crops 24:16-22.

Geetha, S. and A.S. Sudheer. 2000. In vitro propagation of Vanilla planifolia, a tropical orchid. Curr. Sci. 79:886-889.

George, P.S. and G.A. Ravishankar. 1997. In vitro multiplication of Vanilla planifolia using axillary bud explants. Plant Cell Rep. 16:490494.

Giridhar, P. and G.A. Ravishankar. 2004. Efficient micropropagation of Vanilla planifolia Andr. under the influence of thidiazuron, zeatin and coconut milk. Indian J. Biotech. 3:113-118.

Goh, C.J. 1983. In: S.K. Sen and K.L. Giles (eds.). Plant cell culture in crop improvement. Plenum Press, New York, p. 319-336.

Gu, Z., J. Arditti, and L.P. Nyman. 1978. Vanilla planifolia: Callus induction and plantlet production in vitro. Lindleyana 2:48-52.

Kononowicz, H. and J. Janick. 1984. In vitro propagation of Vanilla planifolia. HortScience 19:58-59.

Morel, G. 1960. Producing virus-free Cymbidiums. Amer. Orchid Soc. Bul. 29:495-497.

Murashige, T. and F. Skoog. 1962. A revised medium for rapid growth and bioassays with tobacco tissue cultures. Physiol. Plant. 15:473497.

Philip, V.J. and A.Z. Nainar. 1986. Clonal propagation of Vanilla planifolia (Salisb.) Ames using tissue culture. J. Plant Physiol. 122: 211-215.

Steel, R.G. and J.H. Torrie. 1980. Principles and procedures of statistics. A biometrical approach. McGraw Hill, New York. 